\title{
Remote Cerebellar Hemorrhage after Removal of Large Convexity Meningioma
}

\author{
Dinuj Shrestha $M B B S^{1}$, Janam Shrestha $M B B S^{2}$, Pravesh Rajbhandari $M S^{3}$, Resha Shrestha $M S^{4}$, \\ Basant Pant $\boldsymbol{P h} \boldsymbol{D}^{5}$ \\ 1,2,3,4,5 Annapurna Neurological Institute and Allied Sciences, Kathmandu, Nepal
}

Date of submission: $19^{\text {th }}$ July 2020

Date of acceptance: $17^{\text {th }}$ November 2020

Date of publication: $1^{\text {st }}$ December 2020

\section{Abstract}

Remote cerebellar hemorrhage is a rare postoperative complication. It can occur after infratentorial or supratentorial craniotomies, later being more common. Remote cerebellar hemorrhage is considered to be a self-limited and benign condition. The exact pathophysiology of remote cerebellar hemorrhage remains unclear, but reports have suggested an association with excessive loss of cerebrospinal fluid.

We report a case of remote cerebellar hemorrhage after supratentorial craniotomy for large convexity meningioma without excessive loss of cerebrospinal fluid.

Key words: Cerebrospinal fluid, Craniotomy, Meningioma, Neurosurgery, Remote cerebellar hemorrhage

\section{Introduction}

$\mathrm{R}$ emote cerebellar hemorrhage $(\mathrm{RCH})$ is characterized as bleed in the cerebellum after a surgery has been performed distant from the site of bleeding. $\mathrm{RCH}$ is usually seen to occur between 30 to 60 years of age, however it has been detailed in patients as young as 10 years and as old as 83 years. $^{1}$

Access this article online
Website: https://www.nepjol.info/index.php/NJN
DOI: https://doi.org/10.3126/njn.v17i3.33130
HOW TO CITE
Shrestha D, Shrestha J, Rajbhandari P, Shrestha R, Pant B.
Remote Cerebellar Hemorrhage after Removal of Large Convexity
Meningioma. NJNS. 2020;17(3):63-67

'ORCID id: 0000-0002-7395-8194

${ }^{2}$ ORCID id: 0000-0002-1747-905X

${ }^{3}$ ORCID id: 0000-0001-6093-5850

${ }^{4}$ ORCID id: 0000-0001-5827-0423

${ }^{5}$ ORCID id: 0000-0001-5045-7971

\author{
Address for correspondence: \\ Dr. Dinuj Shrestha \\ Annapurna Neurological Institute and Allied Sciences, \\ Maitighar, Kathmandu, Nepal \\ E-mail: dinuj45@gmail.com \\ Phone: +977-9841211502
}

Copyright (C) 2020 Nepalese Society of Neurosurgeons (NESON)

ISSN: 1813-1948 (Print), 1813-1956 (Online)
$\mathrm{RCH}$ has been reported in the literature after various neurosurgical procedures like clipping of aneurysm, cranial tumor resection, lobectomies and hematoma evacuation. Though it occurred mostly after frontal or frontotemporal craniotomies, there is no evidence to relate it to any specific type of surgery. ${ }^{2}$

The so-called "Zebra sign" pattern, which is characterized by streaks in the cerebellum indicating the spreading of blood in the cerebellar sulcus and which can typically be seen in computed tomography (CT)images, usually occurs in cases of remote cerebellar hemorrhage. ${ }^{3}$ $\mathrm{RCH}$ is a very rare complication that occurs after infra or supratentorial surgeries. ${ }^{4}$

In this case report, we describe a rare entity of $\mathrm{RCH}$ secondary to supratentorial craniotomy for large frontal convexity meningioma.

\section{Case Presentation}

A 55 years old lady with hypertension and type II diabetes mellitus presented with chronic intermittent headache and recently developed forgetfulness and irrelevant talking. She did not have any neurological deficits and her fundoscopy examination was normal. On further evaluation, magnetic resonance imaging (MRI) brain showed large $7.5 \times 6.0$ × $5.8 \mathrm{~cm}$ homogenously enhancing, extra-cranial, right anterior convexity meningioma extending to anterior cranial base with mass effect (Figure 1).

Routine lab investigations including coagulation profile were within normal limit. The patient underwent right fronto-temporal craniotomy, following standard principle gross total removal of tumor was achieved. 


\section{Shrestha et al}

The intraoperative course was uneventful, there was no excessive loss of CSF, no opening of cisterns or ventricle and no brain swelling. Complete hemostasis was achieved before closure over an extradural free drain.

In the immediate post-operative period about one hour after surgery, the patient suffered from decreased level of consciousness (GCS E1V1M1), weakly reactive pupils. Immediate CT scan was negative for operative site hemorrhage but showed remote cerebellar hemorrhage with classical "Zebra sign" pattern (Figure 2). There was no hydrocephalus, basal cisterns and posterior fossa did not have significant compression.
She was managed conservatively with close observation of GCS, pupillary reaction and followed with serial CT scan to observe progression of $\mathrm{RCH}$. On serial scans, there was no increase in hemorrhage, no perilesional edema and normal ventricular size (Figure 3).

After her gradual recovery she was discharged and transferred to rehabilitation center with full consciousness (GCS E4V5M6), Glasgow outcome scale (GOS) of 5 and complete resolution of $\mathrm{RCH}$ in follow-up $\mathrm{CT}$ scan (Figure $3 \mathrm{C})$.

At 6 months follow up in the outpatient department, she had mild weakness of left limbs (MRC grade 4/5), ataxic gait and slurred speech.
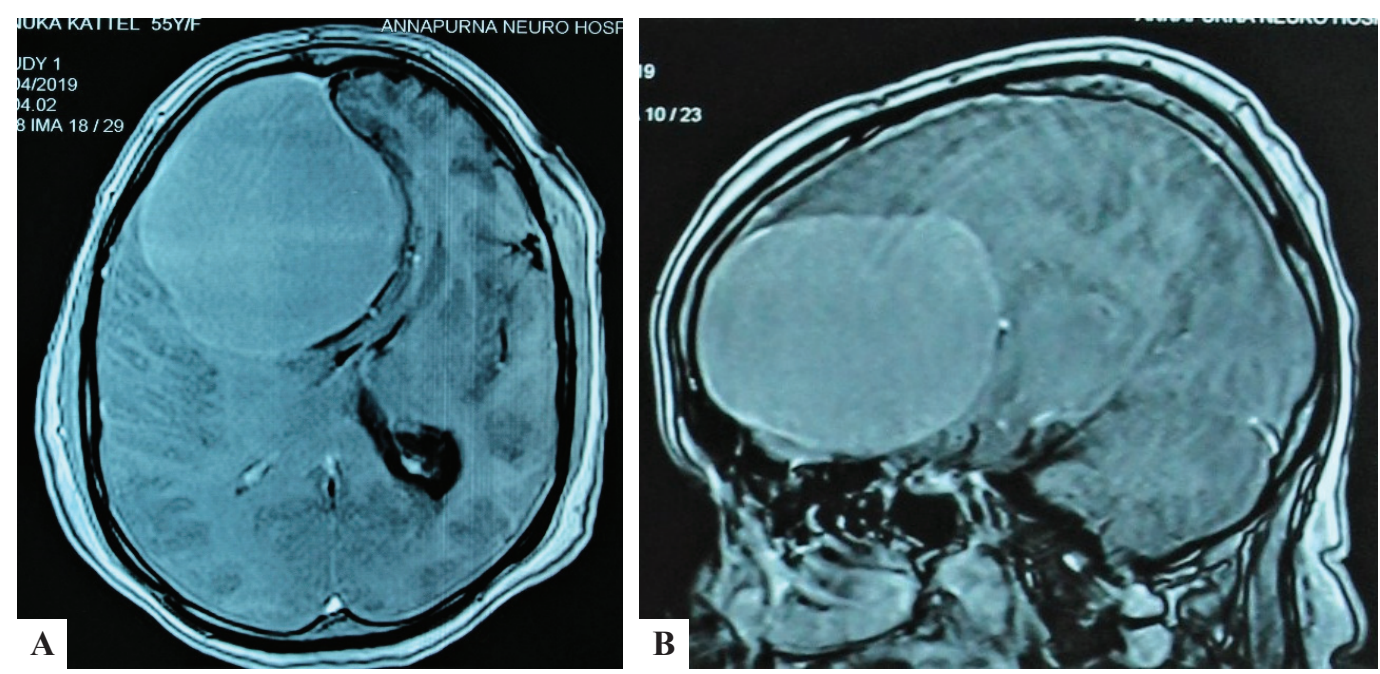

Figure 1: Preoperative MRI showing (1A) large right frontal convexity meningioma in axial view with mass effect and (1B) the sagittal view
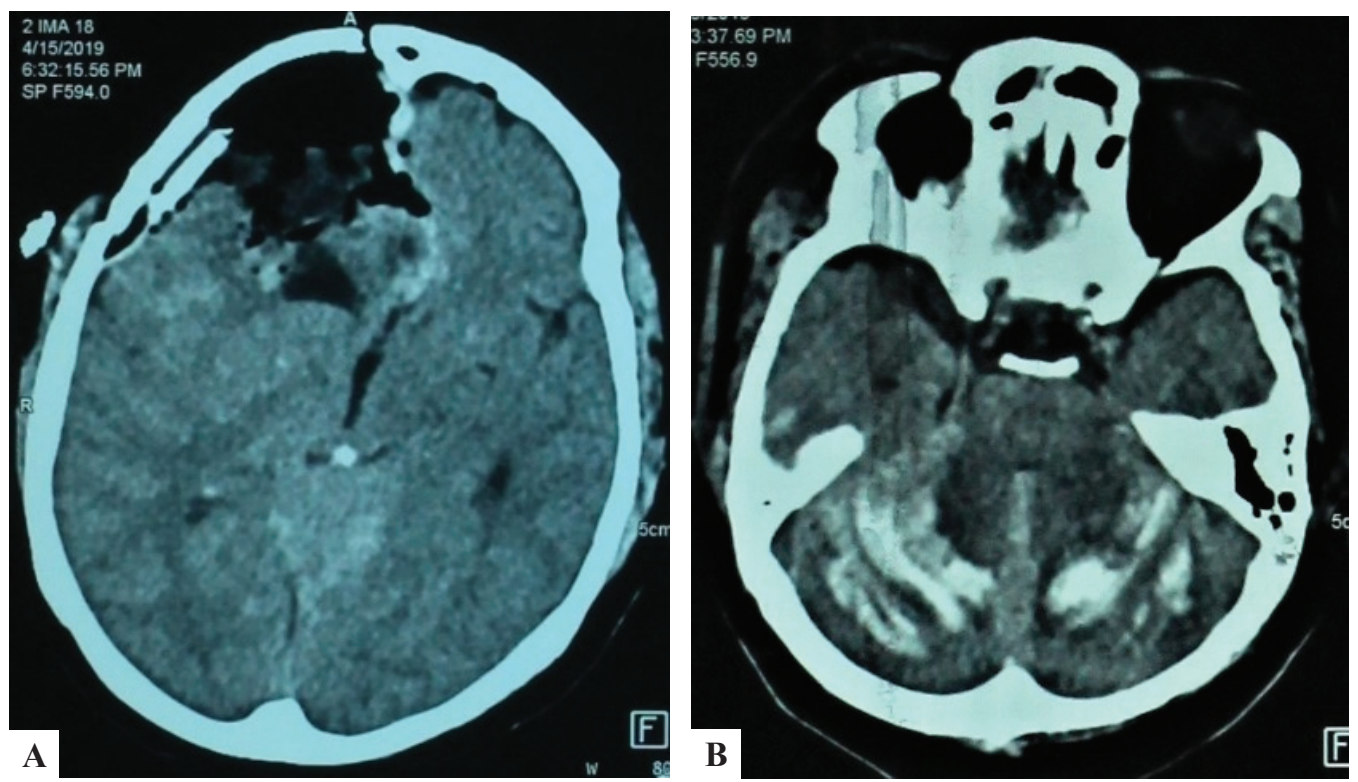

Figure 2: Immediate post-operative CT scan (A) no hematoma in operative site, no hydrocephalus (B)bilateral cerebellar hemorrhage with classical "Zebra sign" 

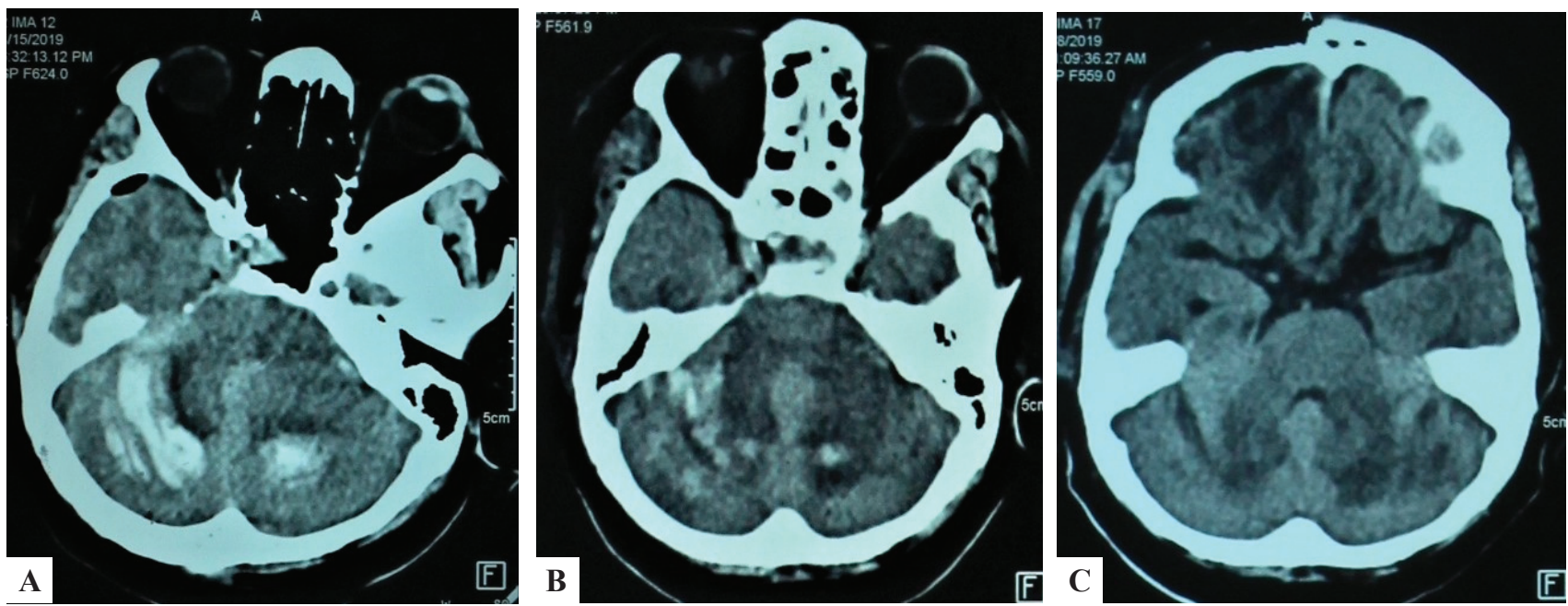

Figure 3: Serial follow up post-operative CT scans showing resolution of RCH on $3^{\text {rd }}$ day $(A), 5^{\text {th }}$ day (B) and at discharge $(C)$
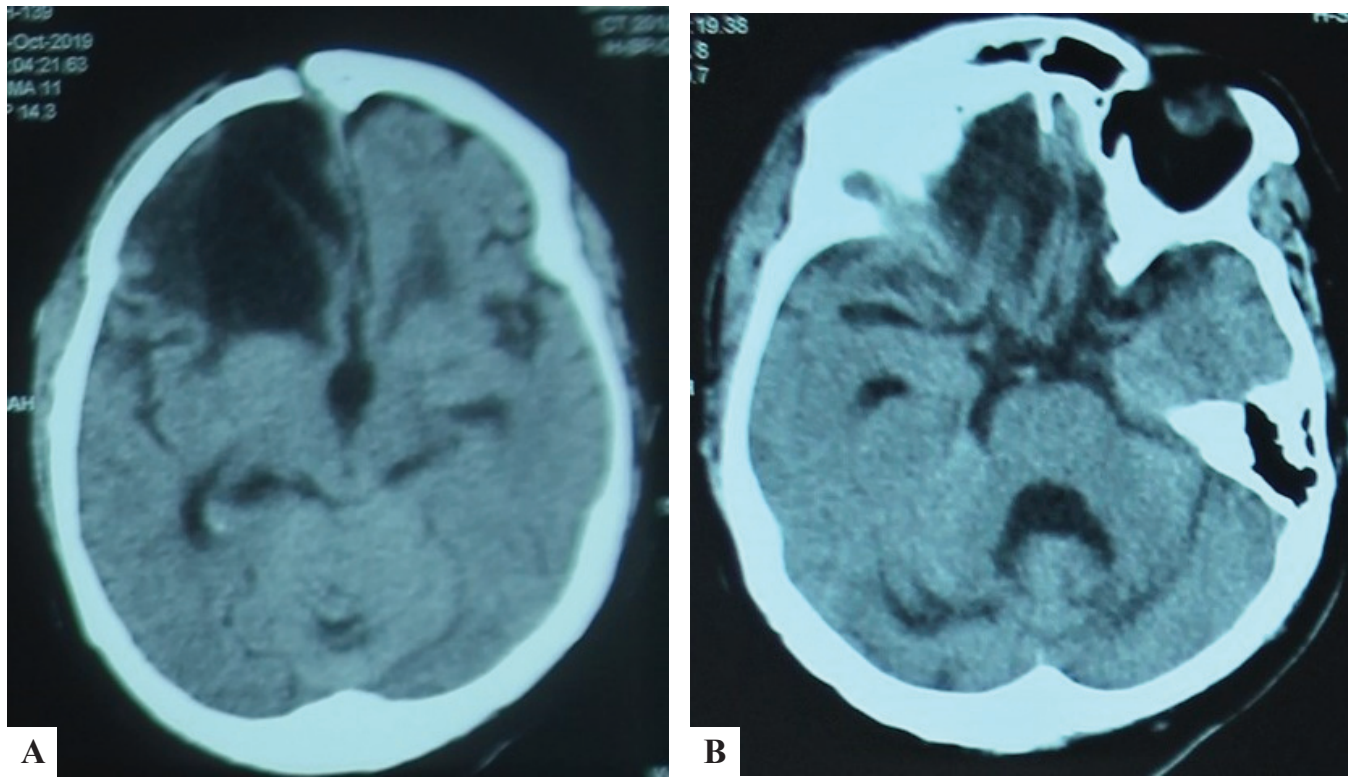

Figure 4: Follow up CT scan at 6 months showing resolution of RCH and gliotic changes over operative site

\section{Discussion}

A remote site hemorrhage (RSH) is an intracranial bleeding that occurs in a location away from the primary site of operation which can occur both in supratentorial region, infratentorial region, or even in both regions simultaneously. ${ }^{4}$ Various known risk factors are coagulopathies and anticoagulant therapy, alcohol abuse and vasculopathies. ${ }^{5,6,7}$ Remote cerebellar hemorrhage after supratentorial surgery is a known but very rare complication with an incidence ranging from $0.08 \%$ to $0.6 \%{ }^{4,8}$ Not only after supratentorial surgeries, this complication has also been reported after spinal procedures. ${ }^{9,10}$
Though the precise pathogenesis of RSH is unknown, CSF hypovolemia due to over drainage seen during decompression has been put forward as the theory of RSH. Bridging veins of the posterior fossa are transiently occluded by caudal displacement of cerebellum which leads to venous engorgement and consequently results in hemorrhagic venous infarction. ${ }^{11}$

Konig et $\mathrm{al}^{12}$ and Yoshida et $\mathrm{al}^{13}$ proposed that $\mathrm{RCH}$ is also related to the postoperative amount of CSF drainage. Negative suction used postoperatively may over drain CSF leading to downward displacement of the cerebellum, causing tearing of the superior cerebellar vein and tributaries. 


\section{Shrestha et al}

In this case, removal of large tumor could cause a rapid decrease in intracranial pressure leading to compensatory acute engorgement of venous sinus and supra-cerebellar bridging veins resulting in cerebellar hemorrhagic venous infarction. ${ }^{14}$

There is no standard management guidelines or protocol regarding $\mathrm{RCH}$. Most cases are asymptomatic or exhibit a benign course, however it can lead to major morbidity ${ }^{11}$ and even death if failed to recognize on time. ${ }^{15}$ Bishokarma et al reported case fatality after surgery for craniopharyngioma due to $\mathrm{RCH} .{ }^{16}$

Site and size of the bleed have an important prognostic value. If hemorrhage is large enough with significant mass effect, obstructive hydrocephalus, surgical intervention might be beneficial. ${ }^{15}$ Smaller bleeds with little or no mass effect, however, seems to be self-limiting and does not require any intervention. Close monitoring in intensive care unit and follow-up CT scan is helpful in assessing the natural evolution of the bleed. ${ }^{2}$

\section{Conclusion}

Though rare, $\mathrm{RCH}$ after any supratentorial craniotomies is possible. We would like to stress the possibility of $\mathrm{RCH}$ after removal of a supratentorial tumor even without excessive loss of CSF, especially in cases with a large tumor. Precautions like over drainage of CSF, opening of ventricle intraoperatively, gradual decompression to maintain intracranial pressure could prevent from this complication. Although it is reported as benign or self-limited, $\mathrm{RCH}$ could be a significant cause of morbidity and mortality if failed to take proper measures both pre and post operatively.

\section{Conflict of Interest: None \\ Source(s) of support: None}

\section{References}

1. Das KK, Nair P, Mehrotra A, Sardhara J, Sahu R, Jaiswal A, et al. Remote cerebellar hemorrhage: Report of 2 cases and review of literature. Asian Journal of Neurosurgery. 2014;9(3):161. https://doi. org/10.4103/1793-5482.142737

2. Amini A, Osborn A, McCall T, Couldwell W. Remote cerebellar hemorrhage. American Journal of Neuroradiology. 2006;27(2):387-90. https://doi. org/10.3174/ajnr.A4528

3. Brockmann MA, Nowak G, Reusche E, Russlies M, Petersen D. Zebra sign: cerebellar bleeding pattern characteristic of cerebrospinal fluid loss: case report.
Journal of neurosurgery. 2005;102(6):1159-62. https://doi.org/10.3171/jns.2005.102.6.1159

4. Honegger J, Zentner J, Spreer J, Carmona H, Schulze-Bonhage A. Cerebellar hemorrhage arising prospectively as a complication of supratentorial surgery: A retrospective study. Journal of neurosurgery. 2002;96(2):248-54. https://doi. org/10.3171/jns.2002.96.2.0248

5. Nagano N, Tabata H, Hashimoto K. Anticoagulantrelated Intracerebral Hemorrhage in Patients with Prosthetic Heart Valves. Neurologia medicochirurgica. 1991;31(11):743-5. https://doi. org/10.2176/nmc.31.743

6. Wijdicks E, Jack Jr CR. Intracerebral hemorrhage after fibrinolytic therapy for acute myocardial infarction. Stroke. 1993;24(4):554-7. https://doi. org/10.1161/01.STR.24.4.554

7. SchützH, Bödeker R-H, Damian M, KrackP, Dorndorf W. Age-related spontaneous intracerebral hematoma in a German community. Stroke. 1990;21(10):14128. https://doi.org/10.1161/01.STR.21.10.1412

8. Toczek MT, Morrell MJ, Silverberg GA, Lowe GM. Cerebellar hemorrhage complicating temporal lobectomy: report of four cases. Journal of neurosurgery. 1996;85(4):718-22. https://doi. org/10.3171/jns.1996.85.4.0718

9. Chadduck WM. Cerebellar hemorrhage complicating cervical laminectomy. Neurosurgery. 1981;9(2):1859. https://doi.org/10.1227/00006123-19810800000016

10. Farag E, Abdou A, Riad I, Borsellino SR, Schubert A. Cerebellar hemorrhage caused by cerebrospinal fluid leak after spine surgery. Anesthesia \& Analgesia. 2005;100(2):545-6. https://doi.org/10.1213/01. ANE.0000143340.51813.6A

11. Friedman JA, Piepgras DG, Duke DA, McClelland RL, Bechtle PS, Maher CO, et al. Remote cerebellar hemorrhage after supratentorial surgery. Neurosurgery. 2001;49(6):1327-40. https://doi. org/10.1097/00006123-200112000-00008

12. König A, Laas R, Herrmann H-D. Cerebellar haemorrhage as a complication after supratentorial craniotomy. Acta neurochirurgica. 1987;88(3-4):1048. https://doi.org/10.1007/BF01404145

13. Yoshida S, Yonekawa Y, Yamashita K, Ihara I, Morooka Y. Cerebellar hemorrhage after supratentorial craniotomy. Neurologia medicochirurgica. 1990;30(10):738-43. https://doi. org/10.2176/nmc.30.738

14. Hara T, Matsuda M, Watanabe S, Nakai K, Yamamoto T, Matsumura A. Remote cerebellar hemorrhage after removal of a supratentorial glioma without 


\section{Remote Cerebellar Hemorrhage after Craniotomy}

perioperative CSF loss: a case report. Case reports in surgery. 2013.. https://doi.org/10.1155/2013/305039

15. Garg K, Tandon V, Sinha S, Suri A, Mahapatra AK, Sharma BS. Remote site intracranial hemorrhage: Our experience and review of literature. Neurology India. 2014;62(3):296. https://doi.org/10.4103/00283886.137027
16. Bishokarma S, Shrestha S, Devkota UP. Remote Cerebellar Haemorrhage after Surgery for Craniopharyngioma: a case report. Nepal Journal of Neuroscience. 2018;15(2):45-8. https://doi. org/10.3126/njn.v15i2.20995 